\title{
HUMAN AS A PHYSIOLOGICAL SOURCE OF DETERIORATION OF THE AIR QUALITY AND COMFORT CONDITIONS INDOORS
}

\author{
Radostina A. Angelova ${ }^{1}$, Peter Stankov ${ }^{2}$, Detelin Markov ${ }^{3}$, \\ Rositsa Velichkova $^{4}$, Iskra Simova ${ }^{5}$
}

\begin{abstract}
It is imperative a model be developed that can assess the difference between the amount of $\mathrm{CO}_{2}$, generated within the human body and the amount of $\mathrm{CO}_{2}$ that is ejected by the body as a function of indoor air parameters. This model would allow the assessment of the amount of the $\mathrm{CO}_{2}$ which is not ejected by the body through exhalation and which have to be neutralized and ejected by the body through other mechanisms or have to be accumulated in the body depots. Currently, there is no experimental data that allows for predicting the amount of $\mathrm{CO}_{2}$, ejected through the blood gas exchange in the lungs as a function of $\mathrm{CO}_{2}$ concentration in the inhaled air. Our study, conducted within the AIRMEN project, aims to research the phenomenology of the human body as a physiological source of the deterioration of both the indoor environment and conditions of comfort and in particular on the indoor air quality. It is based on an experimental investigation of the external result from the human body metabolism and gas exchange in the lungs. The results of this study make it possible to logically define the limits of the permissible $\mathrm{CO}_{2}$ concentration in the indoor air for the different air quality categories indoors.
\end{abstract}

UDC Classification: 628.8, DOI: 10.12955/cbup.v7.1468

Keywords: AIRMEN, $\mathrm{CO}_{2}$, indoor, IAQ, quality, comfort

\section{Introduction}

The primary purpose of planning, designing and constructing residential buildings is to provide the occupants with a healthy and comfortable environment under various weather conditions. The occupants of non-industrial indoor environments perform multiple types of activities, and their physical activity level varies in vast intervals: from sleep (in the residential buildings, hotels, hospitals) through different types of light work (in the residential buildings, schools, administrative buildings) up to intensive physical exercise (fitness centres, sport halls). For their activities, people need energy, which is generated within their bodies mainly by metabolism - Figure 1. To generate the energy that supports their life, people consume oxygen from the inhaled air and nutrients from food. The body uses energy for maintaining its thermophysiological comfort (core body temperature around $37^{\circ} \mathrm{C}$ ) and performing mechanical work (Markov, 2015; Angelova, 2015). As a result of the metabolism, people generate byproducts, a considerable amount of which is ejected by exhalation to the environment as a mixture of gases, mainly $\mathrm{CO}_{2}$ and water vapor.

A model of the $\mathrm{O}_{2}$ consumption and $\mathrm{CO}_{2}$ generation by people is presented in ASTM D6245-2012 (2012). According to the model people consume $\mathrm{O}_{2}$ and eject $\mathrm{CO}_{2}$ to the indoor air at rates that depend on the level of their physical activity, i.e., the rate of the metabolic process, some anthropometric characteristics of the body, and the diet. The model has four significant deficiencies, as defined in Markov (2015):

1. The model is based on basal metabolic data for individuals over the age of 20 , but it must be noted that residential buildings are occupied by children too.

2. The model does not distinguish between the metabolism of women and men.

3. The model is based on the modelling of three quantities only - the level of physical activity of the occupant, the respiratory quotient $(\mathrm{RQ})$ and the surface area $\left(\mathrm{A}_{\mathrm{D}}\right)$ of the body.

4. The model assumes that the entire amount of $\mathrm{CO}_{2}$ generated in the human body is ejected to the indoor air through exhalation. Furthermore, the standard models the volume flow of

\footnotetext{
${ }^{1}$ Technical University of Sofia, Department of Textiles, Centre for Research and Design in Human Comfort, Energy and Environment (CERDECEN), Sofia, Bulgaria, joy_angels@abv.bg

${ }^{2}$ Technical University of Sofia, Department Hydroaerodynmics and hydraulic machines, Centre for Research and Design in Human Comfort, Energy and Environment (CERDECEN), Sofia, Bulgaria, peter.stankov@abv.bg ${ }^{3}$ Technical University of Sofia, Department Hydroaerodymaics and hydraulic machines, Centre for Research and Design in Human Comfort, Energy and Environment (CERDECEN), Sofia, Bulgaria, detmar@ abv.bg ${ }^{4}$ Technical University of Sofia, Department Hydroaerodymaics and hydraulic machines, Centre for Research and Design in Human Comfort, Energy and Environment (CERDECEN), Sofia, Bulgaria, rositsavelichkova@abv.bg

${ }^{5}$ Technical University of Sofia, Department Hydroaerodynmics and hydraulic machines, Centre for Research and Design in Human Comfort, Energy and Environment (CERDECEN), Sofia, Bulgaria, iskrasimova@gmail.com
} 
metabolic $\mathrm{CO}_{2}$ at standard state conditions (101325 $\mathrm{Pa}$ and $\left.273.15 \mathrm{~K}\right)$ only, which is not explicitly stated.

\begin{tabular}{|l|}
\hline Figure 1: Basics of the human body metabolism \\
\hline Source: Authors \\
thermophysiological mechanical work \\
comfort
\end{tabular}

These deficiencies of the standard model may accumulate an error that would lead to inaccurate conclusions and/or incorrect solutions.

Human body characteristics, including the metabolic rate, were under investigation for many years (Harris \& Benedict, 1918; Wang, 1975; Sekhar \& Goh, 2011). Henry (2005) analysed the models for human metabolism together with the "Oxford database": a database of the basal metabolic rate characteristics in humans developed at the School of Biological and Molecular Sciences in Oxford Brookes University. Currently, this is the best database in the field due to the lowest standard errors in it. Markov (2015) presented a theoretical model, developed using the Oxford database that overcame the first three major deficiencies of the model in ASTM D6245 (2012). However, the fourth deficiency of the ASTM D6245 (2012) model cannot yet be overcome due to the lack of experimental data.

Because of the nature of the gas exchange process in the lungs between the blood and the inhaled air, it is logical to assume that when the concentration of $\mathrm{CO}_{2}$ in the inhaled air increases, the amount of $\mathrm{CO}_{2}$ ejected by the blood to the air in the lungs decreases. An expression for quantitative evaluation of this phenomenon is still missing, however. If $\mathrm{CO}_{2}$ in the inhaled air increases, then the amount of $\mathrm{CO}_{2}$ which cannot be ejected by the blood by respiration increases, the last leading to an increase in blood acidity. Under a sufficiently long exposure, this would lead to a weakening of the immune system, as shown in the studies of Robertson (2006), Satish et al. (2012), and Dongmei, Shiming, Zhongping \& Ming-yin Pan (2013).

It is imperative a model to be developed which can assess the difference between the amount of $\mathrm{CO}_{2}$ generated within the body and the amount of $\mathrm{CO}_{2}$ that is ejected by the body as a function of the indoor air parameters. This model would allow the assessment of the amount of the $\mathrm{CO}_{2}$, which is not ejected by the body through exhalation and which have to be neutralized and ejected by the body through other mechanisms or have to be accumulated in the body depots (Dongmei, Shiming, Zhongping \& Ming-yin, 2013).

At present, there is no experimental data that can be used for development of a model for the prediction of the amount of $\mathrm{CO}_{2}$ ejected through the blood gas exchange in the lungs as a function of the $\mathrm{CO}_{2}$ concentration in the inhaled air. Our study, conducted within the AIRMEN project, aims to research the phenomenology of the human body as a physiological source of the deterioration of both the indoor environment and conditions of comfort and in particular on the indoor air quality (IAQ). It is focused on an experimental investigation of the external result from the human body metabolism and gas exchange in the lungs. The results obtained make it possible to logically define the limits of the permissible $\mathrm{CO}_{2}$ concentration in the indoor air for the different air quality categories indoors.

\section{Research Assumptions}

The research on the human body as a source of $\mathrm{CO}_{2}$ generation and deterioration of the IAQ is based on three assumptions - Figure 2. 


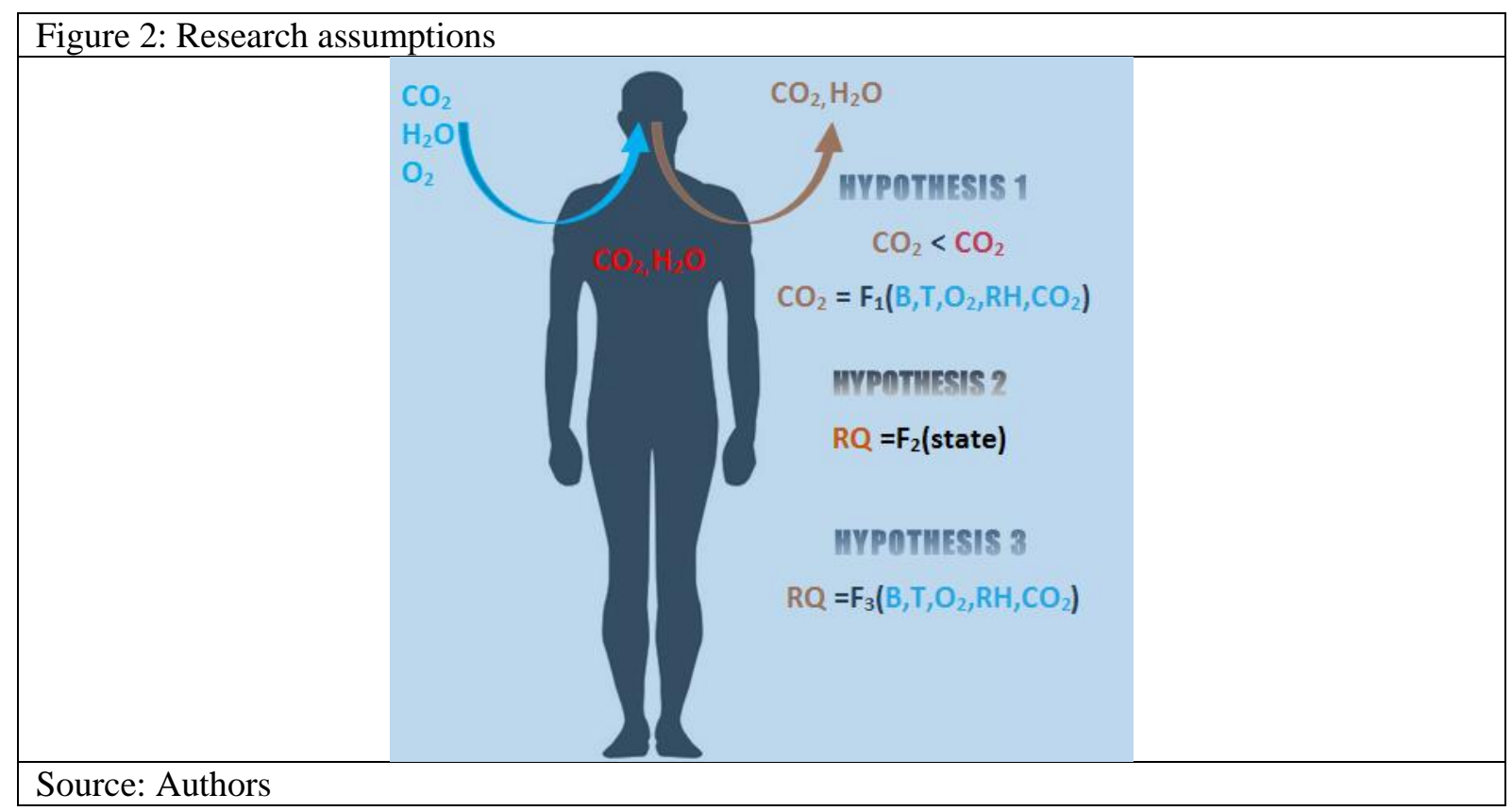

Assumption 1: The human body effect as a pollution source of the indoor air depends on the indoor air parameters. The amount of $\mathrm{CO}_{2}$ rejected from the body by exhalation is always smaller than the metabolic $\mathrm{CO}_{2}$, the amount of $\mathrm{CO}_{2}$ generated within the body, and is preconditioned by the indoor air quality.

Assumption 2: The human body effect as a pollution source of the indoor air depends on human body state. The Respiratory Quotient (RQ), the ratio of the volume of the rejected $\mathrm{CO}_{2}$ to the volume of the consumed $\mathrm{O}_{2}$, under thermal comfort conditions depends on the state of the body - sleep, relaxation, mental work, physical work, i.e., RQ during sleep (in the bedroom) is different from the one at an awakened state (in the classroom/office).

Assumption 3: RQ depends on the indoor air parameters. RQ depends not only on body state, but on indoor air parameters as well: pressure, temperature, relative humidity, and $\mathrm{CO}_{2}$ concentration.

\section{Research Approaches and Activities}

Human sensations and physiological effects of the indoor environment on people are extremely subjective. Moreover, the differences in anthropometric characteristics of people predetermine a different level of their impact on the parameters of the indoor air. That is why human subject experiments are a necessary and reliable tool for investigating the problem.

The metabolic process in the human body and the gas exchange process in the lungs can be characterized by the measurements of the gas compounds in an enclosure with small volume, enough to assure the comfort of a person and to show measurable changes in the indoor air gasses concentration. Therefore, one of the main goals of the study is the design and construction of a climatic chamber. The build of the climatic chamber and all other activities are in line with the interdisciplinary nature of the research topic:

- Design and construction of a climatic chamber;

- Selection of the most appropriate ventilation scheme of the climatic chamber - based on 3D flow simulations by means of CFD (Computational Fluid Dynamics);

- Selection and purchase of specialized measuring equipment for the study;

- Development of a procedure for conducting the experimental study with human subjects;

- Development of a procedure for processing of the experimental data;

- Design of a database for project results;

- Development of a mathematical model for assessment of the physiological impact of people on the indoor air parameters.

\section{Design of the Specialized Climatic Chamber}

The specialized climatic chamber creates and maintains a controlled indoor environment. Thus, the influence of the inhabitants on the composition of the air in the chamber can be measured and studied. 
To assess the geometry of the supply of the fresh air with controlled $\mathrm{CO}_{2}$ concentration and the position of the flow exit, CFD simulations were performed. Figure 4 shows one of the simulated cases, when the fresh air is supplied from the ceiling:

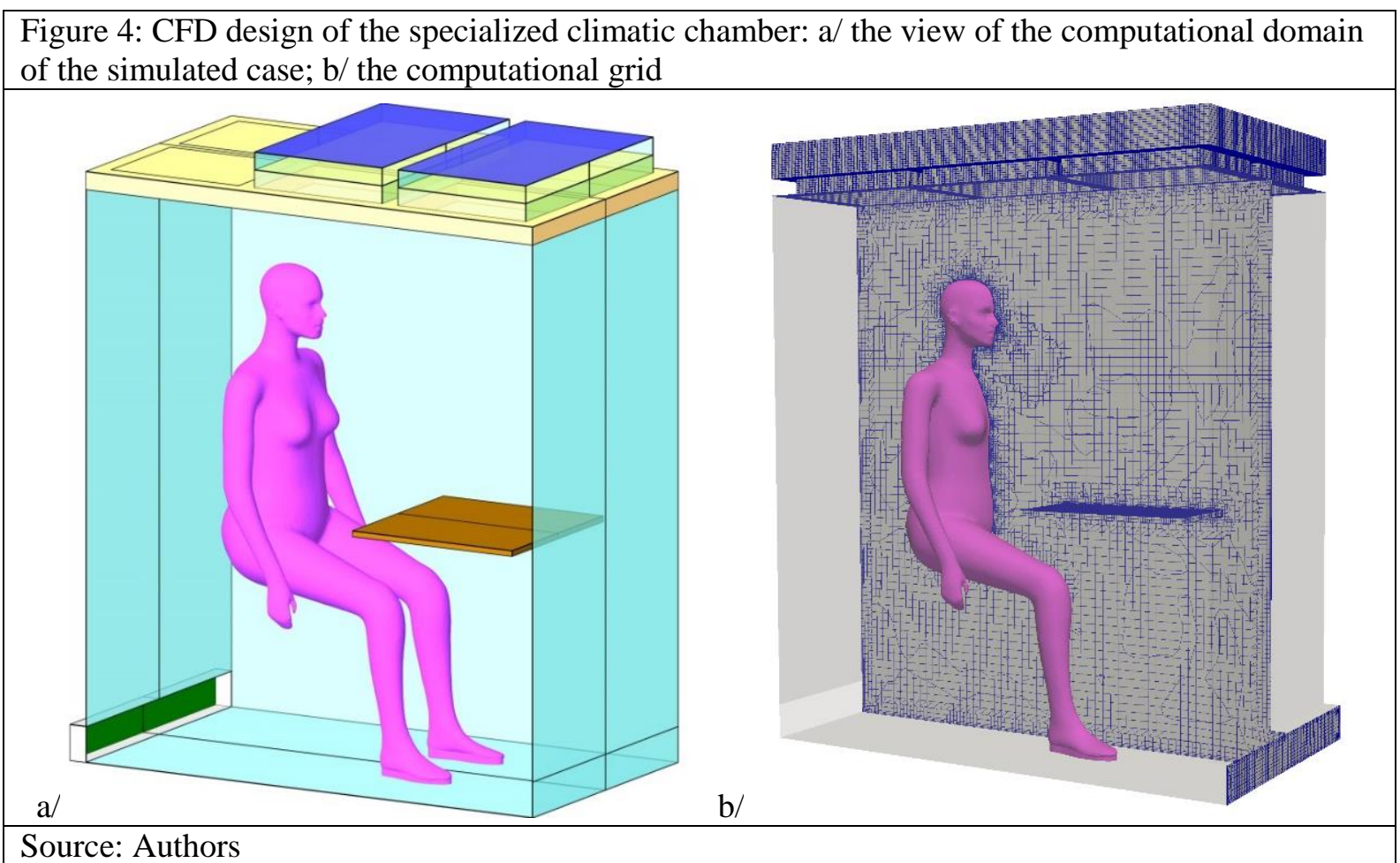

- Supply of the fresh air at the top, $7+31 / s$, only $2 / 3$ of the ceiling, uneven distribution;

- Inlet temperature, $18{ }^{\circ} \mathrm{C}$;

- Broad exit below, behind the human body;

- Inlet filter: $5 \mathrm{~cm}$ thick, pressure losses $20 \mathrm{~Pa}$ at a flow rate of $10 \mathrm{l} / \mathrm{s}$;

- $\mathrm{CO}_{2}$ level 400 ppm.

The results for the $\mathrm{CO}_{2}$ distribution in the chamber are shown in Figure 5. All simulated cases, their analysis and the selected on their basis chamber configuration will be reported in a next paper.

Figure 6 presents a picture of the built climatic chamber for gas measurements.

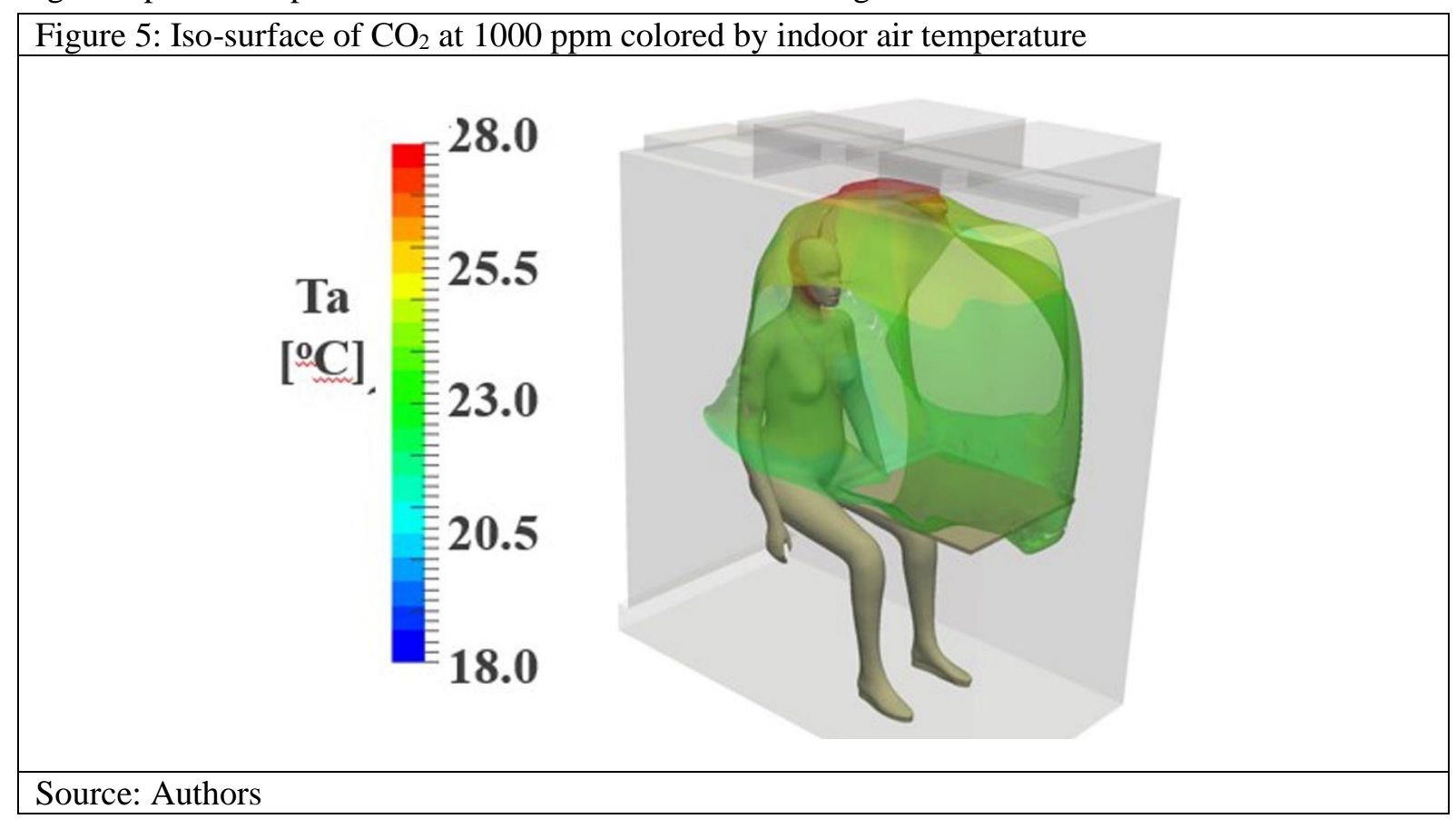




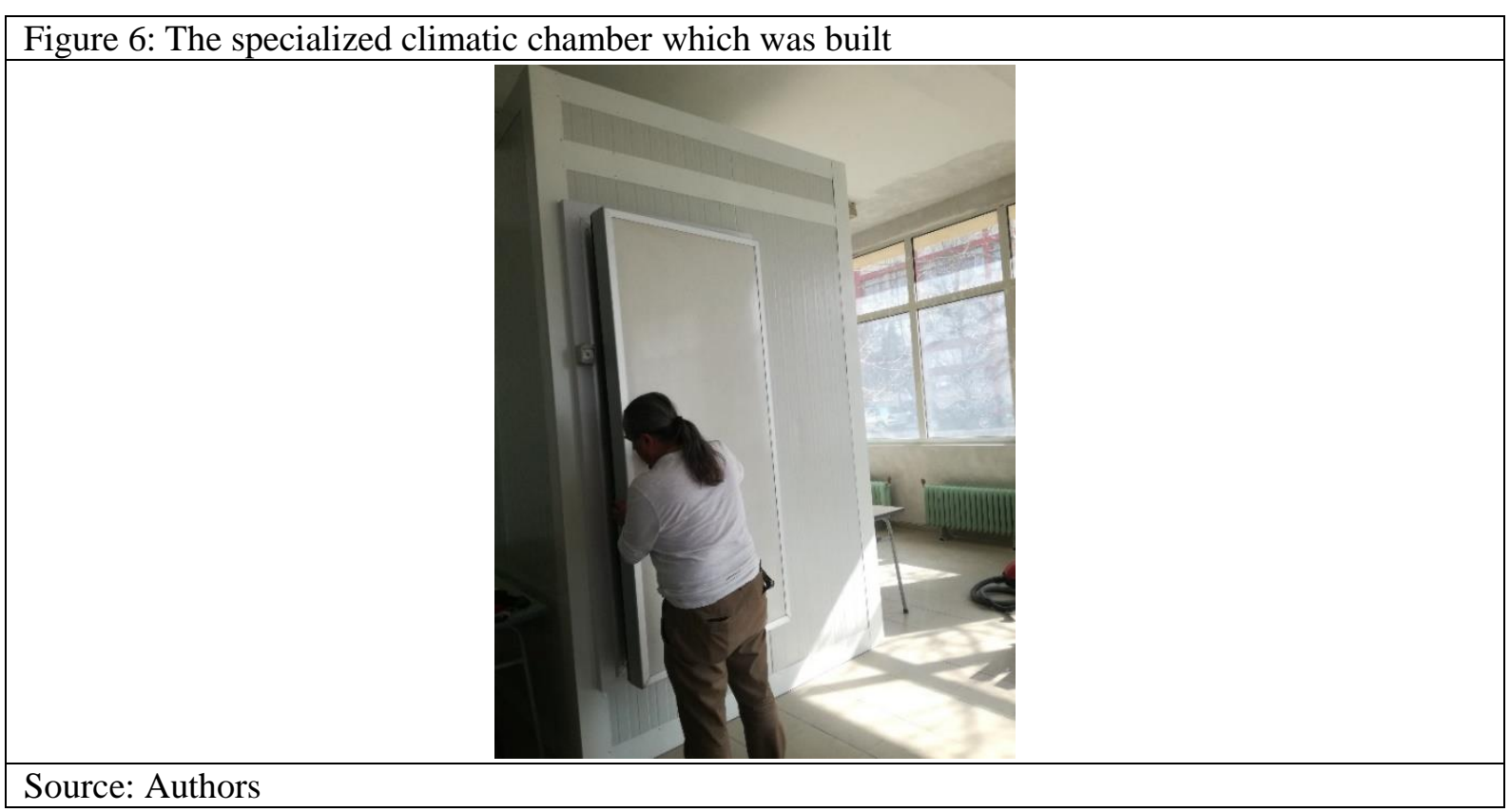

\section{Conclusion}

The AIRMEN project involves an innovative and first-of-its-kind study. A concept was developed for the experimental evaluation of the external result from the human body metabolism and gas exchange in the lungs. A design of a specific climatic chamber was created that allows field studies with human participants and exact measurements of the $\mathrm{CO} 2$ concentration in the inhaled and exhaled air. A CFD simulation study was conducted to determine the basic geometric parameters of the chamber to ensure a perfect mixing of incoming and exhaled air. The built climatic chamber and the developed methodologies can be used in the future for different studies on human metabolism, human thermophysiological comfort and human-indoor air interaction.

\section{Acknowledgment}

This study is part of the project „The Human as a Physiological Source of Deterioration of the Air Quality and Comfort Conditions in Occupied Non-Industrial Indoor Environments", DN17/12/12.12.2017, funded by Bulgarian Science Fund of the Ministry of Education and Science.

\section{References}

Angelova, R. A. (2015). Textiles and human thermophysiological comfort in the indoor environment. CRC Press, Boca Raton, USA. https://doi.org/10.1201/b19118

ASTM D6245 (2012). Standard Guide for Using Indoor Carbon Dioxide Concentrations to Evaluate Indoor Air Quality and Ventilation. D6245-07, American Society for Testing and Materials, Philadelphia, PA. https://doi.org/10.1520/D6245-18

Dongmei, P., Shiming, D., Zhongping, L., \& Ming-yin, C. (2013). Air-conditioning for sleeping environments in tropics and/or sub-tropics-A review. Energy, 51, 18-26. . https://doi.org/10.1016/j.energy.2013.01.009

Harris, J. A., \& Benedict, F. G. (1918). A biometric study of human basal metabolism. Proceedings of the National Academy of Sciences of the United States of America, 4(12), 370. https://doi.org/10.1073/pnas.4.12.370

Henry, C. J. K. (2005). Basal metabolic rate studies in humans: measurement and development of new equations. Public health nutrition, 8(7a), 1133-1152. https://doi.org/10.1079/PHN2005801

Markov, D. (2015). Evaluation of air change rate in occupied spaces with non-organized natural ventilation, $\mathrm{PhD}$ Thesis, Technical University of Sofia.

Robertson, D. S. (2006). Health effects of increase in concentration of carbon dioxide in the atmosphere. Current science, 90 (12), 1607-1609. https://doi.org/10.1371/journal.pmed.1002600

Satish, U., Mendell, M. J., Shekhar, K., Hotchi, T., Sullivan, D., Streufert, S., \& Fisk, W. J. (2012). Is CO2 an indoor pollutant? Direct effects of low-to-moderate $\mathrm{CO} 2$ concentrations on human decision-making performance. Environmental health perspectives, 120(12), 1671-1677. https://doi.org/10.1289/ehp.1104789

Sekhar, S. C., \& Goh, S. E. (2011). Thermal comfort and IAQ characteristics of naturally/mechanically ventilated and airconditioned bedrooms in a hot and humid climate. Building and Environment, 46(10), 1905-1916. https://doi.org/10.1016/j.buildenv.2011.03.012

Wang, T. C. (1975). A Study of Bioeffuents in a College Classroom. ASHRAE Trans, 81, 32-44. https://doi.org/10.1016/j.proeng.2017.10.415 